\title{
A FORMAÇÃO DO PROFESSOR DE GEOGRAFIA: entre passar um estágio e habitar a escola
}

Adriana Maria Andreis ${ }^{1}$

Cristina OTSUSCHi ${ }^{2}$ Gisele Leite De LimA ${ }^{3}$

\section{Introdução}

Neste texto, apresentaremos elementos teóricos e metodológicos relacionados ao Núcleo Geografia da Universidade Federal da Fronteira Sul (UFFS), campus Chapecó, e sua atuação em duas escolas de Educação Básica, nos municípios de Chapecó e Guatambu. O objetivo é problematizar os desafios e as possibilidades relacionados com a qualificação do Estágio Curricular Supervisionado, realizado por meio da modalidade de Residência Pedagógica.

O Estágio Curricular Supervisionado: Práticas de Ensino em Geografia, no curso de Licenciatura em Geografia, na UFFS campus

\footnotetext{
1 Doutora em Educação: Concentração Geografia, professora-adjunta da UFFS, coordenadora de núcleo do Programa de Residência Pedagógica (Geografia) Campus Chapecó, SC, e Erechim, RS. Contato: adriana.andreis@uffs.edu.br.

2 Doutora em Geografia, professora-adjunta da UFFS, docente orientadora voluntária do núcleo do Programa de Residência Pedagógica Multidisciplinar (Geografia), campus Chapecó. Contato: cristina.otsuschi@uffs.edu.br.

3 Doutora pela UFSC (2010), professora do Curso de Graduação em Geografia, Licenciatura, na Universidade Federal da Fronteira Sul (UFFS).
} 
Chapecó, está organizado em quatro etapas, totalizando 420 horas. Apreende atividades que envolvem movimentos de aprendizagem da docência em Geografia, nos anos finais do Ensino Fundamental e no Ensino Médio. Dialogar e conviver com o contexto curricular e entender a gestão da unidade escolar e dos sistemas de ensino, entre outros movimentos realizados com a escola, também, são desenvolvidos como movimento de ensino da atividade de ensinar na escola, realizado pelo professor da universidade.

O Programa de Residência Pedagógica (PRP), com 440 horas de atividades, ou seja, 20 a mais do que prevê o estágio o amplia quantitativamente. Destaca-se, especialmente por abraçar o processo de estágio, complexificando a interação efetiva com a escola-campo, indo além de um sentido de passagem de um período na escola, pois, assume um tom fortemente relacionado à ideia de residir, ou melhor, ao significado de habitar com a escola.

A par desse movimento, trazemos elementos para refletir acerca do processo construído, organizando o texto em partes: inicialmente, apresentaremos os elementos do Estágio Curricular no curso de Licenciatura em Geografia da UFFS, campus Chapecó; na segunda parte, comentaremos as especificidades do subprojeto Geografia da UFFS e refletiremos sobre a relação entre o Estágio e a Residência; e, nas considerações finais, discutiremos as aprendizagens construídas no decorrer do processo.

\section{O Estágio Curricular do Curso de Licenciatura em Geografia da UFFS, Campus Chapecó}

Para melhor compreensão da articulação entre o Estágio Curricular Supervisionado do Curso de Licenciatura em Geografia da UFFS com o Programa Residência Pedagógica, faz-se necessário esclarecer a configuração e as principais características desse tipo de 
estágio. As considerações a seguir sobre o estágio obrigatório tem como base o Projeto Político Pedagógico do Curso de Licenciatura em Geografia de 2013, campus Chapecó.

O Estágio Curricular Supervisionado é fundamental para a formação de professores no curso de licenciatura, foi definido pela Lei n. 11.788/2008, assim como pelas posteriores medidas regulamentadoras. Tem como objetivo principal oportunizar ao estudante experiências com o ambiente profissional, possibilitando a ele vivenciar, discutir e refletir de forma sistemática o seu papel na educação básica e nas modalidades de ensino, como a Educação de Jovens e Adultos (EJA); a Educação de nível técnico; e a sua profissão.

Destacamos que o estágio obrigatório no curso de Licenciatura em Geografia da UFFS, campus Chapecó estrutura-se como uma atividade intrinsecamente articulada com a prática de ensino e com as demais atividades acadêmicas. A organização caracteriza-se com a presença do coordenador de estágio, o professor da disciplina de estágio e, quando necessário, o orientador para acompanhar o estagiário em suas atividades na escola-campo, auxiliando o professor de estágio. Nas escolas, há o supervisor externo para melhor organização dos estágios obrigatórios dos diferentes cursos.

O Estágio Curricular Supervisionado: Prática de Ensino em Geografia é dividido em quatro estágios, que são ofertados a partir da metade do curso e possuem abordagens diretas, teórica e conceitualmente, com as demais disciplinas, por exemplo, a Didática Geral e a Didática em Geografia.

Os Estágios I e III possuem seis créditos cada equivalendo a 90 horas, e são realizados nos Ensinos Fundamental e Médio, respectivamente. Nesses estágios, os estudantes têm a possibilidade de observar os diferentes processos educativos escolares, assim como os subsídios conceituais, didáticos e metodológicos, tendo a noção da importância do professor-pesquisador para o ensino da Geografia. 
Já nos Estágios II e IV, os estudantes elaboram propostas pedagógicas para aulas de Geografia, exercitando a prática docente nas turmas de Ensino Fundamental e Ensino Médio, respectivamente. Os estágios com regência possuem oito créditos cada e correspondem a 120 horas. É assim que os estágios obrigatórios totalizam 420 horas, possibilitando experiências em diferentes fases no âmbito escolar.

Essa divisão em quatro estágios possibilita as etapas de: apreensão da realidade da escola campo de estágio; elaboração de plano de aula; e a execução da proposta de ensino na escola, relatório final de estágio e participação de seminário para socialização e avaliação do estágio realizado. Prioriza-se o estágio de forma individual, principalmente a regência.

O estagiário precisa conhecer e compreender o futuro ambiente profissional, sendo previstos, nos estágios obrigatórios, a participação em reuniões pedagógicas e nos intervalos dos professores e dos alunos. Sendo fundamental conhecer os diferentes ambientes, o Projeto Político Pedagógico e a estrutura, a organização e o funcionamento da escola campo. As diferentes fases do estágio curricular obrigatório, como planejamento, orientação, acompanhamento e avaliação, são coordenadas pelos professores das disciplinas de estágio.

Ressaltamos o que foi mencionado anteriormente, o contato com o ambiente escolar é fragmentado em experiências no Ensino Fundamental com os Estágios I e II, como no Ensino Médio, por meio dos Estágios III e IV. Sendo que há separação em observação e a prática supervisionada, ou seja, a regência.

Para a formação do professor, caracterizada pela análise sustentada pedagogicamente, assim como pela observação dos processos educativos escolares, subsídios conceituais, didáticos e metodológicos, evidenciamos a importância de ampliar a vivência escolar e a imersão possibilitada pelo Programa Residência Pedagógica. A observação e a regência nos Ensinos Fundamental e Médio nesse 
Programa possuem outra dinâmica em relação ao estágio obrigatório. Portanto, vamos nos dedicar, agora, a essa discussão.

\section{A Experiência do Núcleo Geografia da UFFS, Campus Chapecó no PRP}

O PRP compreende um total de 440 horas, ou seja, tem um alcance temporal que abarca as atividades de Estágio Curricular, implicando maior proximidade entre escola e universidade e, concomitantemente, oportunizando uma ressignificação da concepção de estágio. Envolve atuação de professores da universidade (coordenador e voluntários) e professores da escola (coordenador, nominado como Preceptor e apoiadores) que, em diálogo, ensinam e coordenam os Residentes (acadêmicos estagiários) nas atividades de aprender e exercitar o ensinar Geografia na Educação Básica.

No contexto do PRP da UFFS, estabelecemos objetivos como horizontes que compreendem a relação entre o ensino e a aprendizagem do professor, envolvendo aspectos conceituais e metodológicos da área da Geografia. Consideramos, nesse processo, as discussões dos pesquisadores que oferecem elementos para afirmar a importância da práxis nas aprendizagens formativas do professor de Geografia.

A relação de aprendizagem da docência envolve elementos conceituais e saberes dos professores. Tardif $(2005$, p. 245) menciona esse entrecruzamento como essencial, afirmando a fundamentalidade do diálogo entre os saberes profissionais dos professores e os conhecimentos universitários como "elementos para uma epistemologia da prática profissional dos professores" e seus efeitos para a formação do docente. Encontra-se essa perspectiva do estudioso da educação, com a ideia analisada pelo pesquisador da educação geográfica, Dr. Marcelo Garrido Pereira (2012, p. 174), quando chama a atenção para o movimento de "busca de um lugar negado" às 
relações entre universidade e escola, no processo de formação do professor de Geografia. Esse lugar é o reconhecimento de que a escola e o professor têm saberes profissionais importantes e que os formadores da universidade precisam reconhecer e considerar na formação do professor de Geografia. Trata-se de um entendimento de diálogo multilateral com a escola.

Callai (2013) fala sobre a formação do profissional da geografia apresentando o professor e as suas aprendizagens formativas sempre em diálogo com a escola. Essa perspectiva é apontada há muitos anos pelos pesquisadores da Educação, da Geografia e de outras áreas do conhecimento. Em outros estudos realizados (ANDREIS, 2012; 2015), argumenta-se acerca da importância desse reconhecimento e do respeito à escola e aos saberes dos professores como determinantes do lugar da universidade na escola.

Para essas discussões, tomamos como elo fundamental o encaminhamento de atividades para o aperfeiçoamento da formação dos discentes no curso de Licenciatura em Geografia, por meio do desenvolvimento de projetos na escola, para fortalecer o campo da prática. Os licenciandos exercitam de forma interativa a relação entre teoria e prática profissional docente, utilizando coleta de dados e diagnóstico sobre o ensino e a aprendizagem escolar. Para tanto, tencionam os conhecimentos da mediação pedagógica e a experimentação de diferentes metodologias de ensino, utilizando também diferentes recursos.

Esse movimento permite um processo de reformulação do estágio supervisionado no curso de Licenciatura em Geografia, tendo por base a experiência da residência pedagógica, também como meta importante. $\mathrm{O}$ fortalecimento, a ampliação e a consolidação da relação entre a UFFS e as escolas de Educação Básica (Ensino Fundamental e Médio), promove a sinergia entre a entidade que forma e a que recebe o egresso da licenciatura e estimula o protagonismo 
das redes de ensino na formação de professores. Ao encontro disso, promovemos um processo de reflexão para a adequação dos currículos e das propostas pedagógicas dos cursos de formação inicial de professores da Educação Básica com relação às orientações da Base Nacional Comum Curricular (BNCC).

Nesse processo relacional entre universidade e escola, com vistas à formação do professor de Geografia, está presente a compreensão da dimensão formativo-educativa implicada nos pressupostos teóricos e metodológicos da educação geográfica. Pois, o desenvolvimento de atividades, envolvendo docentes e discentes da escola pública e da UFFS, relacionadas às aprendizagens da docência em Geografia (Ensino Fundamental - anos finais e Ensino Médio), vinculadas ao ensino e aprendizagem, considera as perspectivas dos conhecimentos conceituais e categorias da Geografia (lugar, paisagem, território, região, redes, cidade e área urbana, de campo e rural, escalas etc.), e da mediação pedagógica dialógica, assumida como didática em Geografia.

Também, nessa implicação com as escolas de Educação Básica, ocorre o estudo de textos que contemplam os pressupostos teórico-metodológicos para ensinar geografia na perspectiva da educação geográfica nos anos finais do Ensino Fundamental e no Ensino Médio. Estes materiais se baseiam em análises sustentadas geograficamente, considerando pressupostos de mediação pedagógica e científico-didática à constituição do professor-pesquisador de Geografia, na Educação Básica.

Cabe então, um processo conjunto para elaborar propostas pedagógicas para o ensino de Geografia na Educação Básica, exercitando a prática docente por meio de atividades de observação, monitoria e desenvolvimento de atividades educativo-geográficas com a escola. Também é preciso construir, pela análise sustentada pedagogicamente e pela observação dos processos educativos escolares, 
subsídios conceituais, didáticos e metodológicos, para a constituição do professor-pesquisador. Marques (2006, p. 18) alega que se trata de "aprender a pesquisar ensinando a pesquisar". Nagle (apud MARQUES, 2006, p. 134) afirma que

[...] é preciso começar a pensar, de forma sistemática e produtiva, nos modos de articulação - nas suas diversas dimensões entre o ensino e a pesquisa, em lugar de decretar, de forma simplista, que essas duas funções são, por natureza, indissociáveis. Se elas têm de ser associadas, a associação precisa ser construída. Esta é, ainda, uma tarefa que cabe à Universidade realizar.

A relação de ensinar a ensinar tem esse elemento que permite assumir concretamente a aproximação entre ensino e pesquisa. Além disso, cabe à universidade o compromisso de promover essa interlocução, pois ela tem seu papel na realização de ensino, incorporando pesquisa e extensão.

Outro aspecto presente no PRP Geografia envolve acompanhar aulas, elaborar propostas pedagógicas e exercitar a prática de regência em Geografia com a escola. E um aspecto importante é a compreensão da instituição escolar, sua organização e funcionamento, relações, processos de gestão, coordenação pedagógica, suas práticas curriculares, formativas, de produção do conhecimento e inclusivas. Para essa compreensão, apoiou-se em Marques (1993, p. 110), pois, segundo o autor, "[...] não se ensinam ou aprendem coisas, mas relações estabelecidas em entendimento mútuo [...]”. A sequência dos argumentos do referido Filósofo da Educação apreendem nosso empenho, pois o processo relacional não prevê “[...] chegar a soluções dadas às questões/problemas, mas de inventar em cada situação e por cada comunidade de sujeitos, os conceitos com os quais irão operar sobre os temas que analisam". Trata-se de entender que na relação entre Estágio e Residência, 
Os estágios durante o curso todo devem oportunizar ao estudante as aprendizagens das práticas que se desenvolvem. Não vai o aluno à realidade vivida para ensinar algo ou levar-lhe soluções, mas para percebê-la na concretude do dia-a-dia e aprender das práticas em desenvolvimento naquele concreto campo empírico. (MARQUES, 2006, p. 137)

Essa abertura e essa qualificação do estágio permitem que possamos pensar o estágio como um processo de morar ou habitar, residindo na escola.

\section{Passar um Estágio na Escola ou Habitar a Escola}

A diretora de uma das escolas comentou em um encontro no qual analisávamos os caminhos que vínhamos realizando: "No início, preocupava-me em preparar toda a escola (deixar tudo limpinho e arrumado), para os dias nos quais receberíamos a visita dos residentes". "Depois", diz a gestora, "[...] entendi que como eles estariam conosco quase todos os dias e turnos da semana, então, não são mais visitas; moram na escola e irão entender os desafios e as possibilidades de ensinar, nesse contexto complexo".

Nesse modo de estagiar com a escola, partimos do pressuposto de que: "aprende-se a ser professor de Geografia com a escola", não para a escola e pela escola. Aprende-se com a escola e com os seus sujeitos, considerando sempre que todos somos produtos e produtores de espaço geográfico.

Nos diálogos com as escolas, notamos o apoio e o auxílio entusiasmado das equipes diretivas das escolas ao PRP, colocando as instalações e os documentos delas à disposição da universidade e colaborando na organização dos horários de trabalho entre preceptores, acadêmicos e professores. Também os professores das diferentes áreas e os alunos se mostraram sempre animados com esse processo 
relacional com a universidade, pois viam nisso a abertura da escola e de outras possibilidades, paralelamente à qualificação dos futuros professores que atuarão nas escolas.

Há renovação na escola e na formação do professor de Geografia na universidade. Pois, a interlocução ocorre de modo mais intenso e denso, por meio do PRP, tendo em vista, também, a construção de aprendizagens emancipatórias durante o aperfeiçoamento da formação dos discentes/residentes do curso de Licenciatura em Geografia.

Por meio do programa, as práticas fortalecem a práxis, mobilizando toda a comunidade escolar e exercitando de forma ativa a adequação dos currículos e das propostas pedagógicas dos cursos de formação inicial de professores de Educação Básica para as orientações da BNCC.

A especificidade de incluir o estágio como parte de um processo mais complexo, menos passageiro, tem fundamentalmente um tom de convivência com a escola. Trata-se sim da realização de estágio curricular supervisionado, mas não apenas visitando esporádica e rapidamente a escola, e sim habitando a escola. $\mathrm{O}$ que pode se aproximar da ideia de residência médica, na qual o professor da universidade dialoga e acompanha mais proximamente um grupo de alunos a uma unidade de ensino, potencializando aprendizagens mútuas da escola e da universidade e, especialmente, entre ambas. Pela sua aproximação com a concepção da residência médica ${ }^{4}, o$ Programa Residência Pedagógica prevê o acompanhamento do estagiário por um professor experiente, concomitantemente à formação do acadêmico e em permanente interlocução com o professor da universidade.

\footnotetext{
4 Além das singularidades temáticas e de tipos de atividades, a diferença principal é que a residência médica ocorre após a formação inicial, enquanto a residência pedagógica, na nossa proposta, implica acompanhamento ainda durante o curso de licenciatura.
} 
Esse movimento se justifica porque nos diálogos reflexivos que mantemos com as escolas em geral (professores, coordenadores de estágio e gestores), com os colegas professores e servidores da Gerência de Educação (GERED), e destes em interlocução com os estudos dos referenciais teóricos na universidade, vêm se demonstrando ser importante ressignificar as aprendizagens com os estágios, aproximando mais esses âmbitos (universidade e escola) de formação dos professores de Geografia. Assim, experimentando essa "aprendizagem de professor da Educação Básica”, podemos concentrar esforços com os estagiários em um menor número de escolas.

\section{Considerações Finais}

No encontro das discussões dos pesquisadores da Geografia e da Educação, entendemos que alguns avanços qualificam a formação do professor de Geografia, pois tem como ponto forte o respeito ao saber do professor e da escola. Como afirma Tardif (2005), há o entendimento de que o conhecimento do professor é sempre provisório (ANDREIS, 2015) e que isso é válido, também, para o professor da universidade.

Nesse contexto, entre os avanços que compreendemos envolver a Residência Pedagógica, destacamos:

a) A aprendizagem mútua, nos âmbitos da universidade e da escola, do ensino de saberes e conhecimentos do professor de Geografia, assumindo efetivamente a reunião entre ensino, pesquisa e extensão.

b) $\mathrm{O}$ acompanhamento mais focado e organizado pelo professor da universidade para ensinar a aprender a ser professor de Geografia, em diálogo com as vivências dos professores de Geografia, gestores e alunos e estudando os documentos da unidade escolar e os modos de gestão. 
c) A potencialização de aprendizagens dos professores das escolas, com os estudos e as vivências dos estagiários e, paralelamente, a coadunação de modo mais organizado e focado tanto na coordenação de horários, atividades e participações quanto na contribuição na formação do estagiário.

d) A facilitação dos diálogos da universidade com os professores da escola e o acompanhamento mais interativo dos estágios na Educação Básica.

e) A convivência em um formato laboratorial entre universidade e escola, permitindo tanto para a escola como para a universidade a atualização dos debates e das reflexões, aproximando-se da noção de formação continuada para os atores implicados.

f) O fortalecimento do diálogo acerca das aprendizagens entre os estagiários e deles com todos os sujeitos da escola.

g) A reunião de diferentes contextos de aprendizagem para assumir, efetivamente, que o campo de estágio compõe parte da aprendizagem de professor de Geografia na Educação Básica.

h) A abertura para a pesquisa, pois compreende reflexão e sistematização, entendidos como avanços científico-acadêmicos.

i) A presença efetiva e mais continuada do professor da escola no contexto universitário (inclusive nas aulas e nos seminários de estágio).

j) A formação continuada para os professores da escola e da universidade, envolvidos no processo.

k) A interação no processo de avaliação dos residentes.

1) A aproximação desafia os professores da escola para a pós-graduação stricto sensu.

m) A experimentação de estratégias metodológicas com a escola e com seus recursos. 
Esses entrelaçamentos permitem entender e propor que residir não é apenas ser visita na escola, como mencionou a gestora da escola. Assume sim um papel de que se aprende a ser professor de Geografia com a escola, reconhecendo suas construções históricas e estendendo a mão para com ela construir caminhos de mãos dadas. Trata-se de atitude e de postura abertas e hermenêuticas, assumidas por todos os envolvidos, como um elo da qualificação na formação do professor de Geografia apreendendo. Infere, ainda, reconhecer que essa práxis é um exercício de conexão entre ensino, pesquisa e extensão.

\section{Referências}

ANDREIS, Adriana Maria. Ensino de Geografia: fronteiras e horizontes. Porto Alegre, RS: ComPasso, 2012.

ANDREIS, Adriana Maria. Ser professor: uma (auto) aprendizagem provisória. In: CALLAI, H. C.; TOSO, C. I. Diálogos com professores. Ijuí, RS: Editora da Unijuí, 2015. p. 59-78.

BRASIL. Ministério da Educação; Secretaria de Educação Básica; Conselho Nacional de Educação. Base Nacional Comum Curricular (BNCC). Brasília: MEC, 2017. Disponível em: http://basenacionalcomum.mec.gov.br/images/BNCC_EI_EF_110518_versaofinal_ site.pdf . Acesso em: 15 fev. 2019.

CALLAI, Helena Copetti. A formação do profissional da Geografia: o professor. Ijuí: Editora UNIJUÍ, 2013.

CURSO DE GEOGRAFIA. Projeto pedagógico do curso de graduação em Geografia - licenciatura. Chapecó, SC: Universidade Federal da Fronteira Sul, 2013. Disponível em: https://www.uffs.edu. br/atos-normativos/ppc/cclgch/2013-0002. Acesso em: 10 abr. 2019. 
MARQUES, Mario Osorio. Conhecimento e modernidade em reconstrução. Ijuí, RS: Editora da Unijuí, 1993.

MARQUES, Mario Osorio. Escrever é preciso: o princípio da pesquisa. Ijuí, RS: Editora da Unijuí, 2006.

PEREIRA, Marelo Garrido. O imperativo situacional do ensino geográfico: em busca do lugar negado e do território perdido. In: CASTELlAR, S.; CAVALCANTI, L.; CALLAI, H. Didática da Geografia: aportes teóricos e metodológicos. São Paulo: Xamã, 2012. p. 173-185.

TARDIF, Maurice. Saberes docentes e saber profissional. Petrópolis: Vozes, 2005. 